\title{
Did the Covid-19 Pandemic Affect the Junior Primary Learners' Fine Motor Skills? A Literature Review
}

\author{
Natalia S. Intja ${ }^{1}$, Kretha Mbambo², Martha Nahole ${ }^{3}$ \\ anreino@unam.na \\ 1 Lecturer in the Faculty of Education and Human Sciences, Department of Intermediate and Vocational Education, \\ University of Namibia's Rundu Campus \\ (nreino@unam.na)
}

2Lecturer in Faculty of Economics and Management Sciences, University of Namibia Rundu Campus

3 Lecturer in the Faculty of Education and Human Sciences, Department of Intermediate and Vocational Education, University of Namibia's Rundu Campus

\begin{abstract}
This study aims at providing information on how the Covid-19 pandemic affect the fine motor skills of learners in the Junior Primary Phase to deduce ways to prevent learners' fine motor skills from diminishing. This study uses a literature review method using a comprehensive strategy of searching for articles in various research journal databases. The databases used are PubMed, Education Resources Information Center (ERIC) and Directory of Open Access Journals. The key words used in the search were Covid-19, Primary School Learners, Fine Motor Skills and Hand Writing. 15 articles were obtained from the searched databases and only five were analysed due to their relevance to this paper's title. The articles were analysed using the following headings, author (s) and year of publication, title of the research, place or country of publication, name of database, sample and study design and results. The results of this study confirm that the Covid-19 pandemic have resulted in a decrease in fine motor skills due to children being scarfolded by inexperienced beings in terms of how to grasp a pen and how to position a book or paper whilst writing. Parents or guardians should also play their role in ensuring that their children grasp the fine motor skills and the Ministry of Education in Namibia should impose strict measures to regulate the Covid-19 pandemic while learners in the Junior Primary Phase attend face to face learning without alternating to get the hands-on fine motor skills from their teachers.
\end{abstract}

Keywords: Covid-19; Primary School Learners; Fine Motor Skills; Hand Writing

\section{Introduction}

Covid-19 has affected the approach the education fraternity conducts its day-after-day activities. Moreover, faculties worldwide and in African countries to be precise within the Kavango East Region in Namibia have 
adopted a mitigating strategy of teaching learners remotely. As a result, learners within the Junior Primary part (Grades 0-3) needs to master the abilities of writing. Remote teaching has led to shifting the lecturers' responsibilities to the fogeys or guardians in serving to their youngsters to find out a way to write as a result of teachers send activities that folks will administer to their youngsters. kinaesthetic, visual motor, and motor designing area unit additional closely associated with handwriting (Tseng and Cermak, 1993). likewise, as handwriting, visual-motor coordination skills, motor designing, psychological feature and sensory activity skills, a mixture of tactile and kinaesthetic sensitivities area unit advanced perceptual-motor skills (Maeland, 1992). what is more, handwriting seems as a perceptual-motor talent noninheritable through repetitive observe (Feder \& Majnemer, 2007) associate degreed is commonly given as an example of motor talent noninheritable through procedural learning processes (Wilhelm, Prehn-Kristensen, \& Born, 2012). Handwriting is really a complex and advanced talent. correct handwriting needs fine motor skills, seeing, psychological feature integration, and maturation (Volman, Van Schendel, \& Jongmans, 2006; Shams \& Kim, 2010). Therefore, fine motor skills area unit vital as a result of properly fashioned letters will solely be created with force management and correct temporal arrangement of coordinated finger, hand, and arm movements (Alston \& Taylor, 1987). There are a unit several basic talent elements which will interfere with handwriting performance. Before beginning the handwriting method, youngsters have to be compelled to develop preparation skills to create letters, like the event of huge and little muscles, seeing, fine motor skills, and hand manipulation skills (Lamme, 1979). once repetition letters and words, youngsters needn't solely keep the task in mind, attention, visual and manual coordination, however additionally management of fine movements and enough power of the finger and also the hand (Stevenson and simply, 2014). it's seen that motor ability measures associated with handwriting production have associate degree indirect impact on handwriting in school-age youngsters (Berninger, 2009). getting handwriting skills at the start of education is that the basis of future educational success (Cahill, 2009). it's seen that handwriting errors within the grade of grammar school area unit associated with educational accomplishment up to grade six (Moore and Rust, 1989). Therefore, it's essential to develop intervention ways to facilitate the event of graphomotor and skills fine motor of 1 st-grade youngsters in grammar school.

The same line of thought has been maintained by Akin (2019) that fine motor skills area unit skills needed for learners to regulate and strengthen their muscles. It therefore represents hand-eye coordination skills and handwriting. Learners World Health Organization failed to grasp the fine motor skills show poor handwriting skills, such a learner could also be “directed to medical specialty physiotherapy services' (Bringham \& Snapchilds, 2019). This study, it's aimed to research however the Covid-19 pandemic affects the fine motor skills 
of learners within the Junior Primary phase to deduce ways in which to stop learners' fine motor skills from decreasing.

\section{Materials and Methods}

This study adopted a literature review methodology employing a comprehensive strategy of sorting out articles in numerous analysis journal databases. The databases used area unit PubMed, Education Resources Information Center (ERIC), and Directory of Open Access Journals. The keywords utilized in the search were Covid-19, grammar school Learners, Fine Motor Skills, and Hand Writing. fifteen articles were obtained from the searched databases and solely 5 were analyzed thanks to their relevance to the present paper's title. The articles were analyzed mistreatment the subsequent headings, author (s) and year of publication, the title of the analysis, place or country of publication, name of the information, sample, study style, and also the results of every article. 
The results of the research used in this literature review are as follows:

Table 1. Review of Research Results

\begin{tabular}{|c|c|c|c|c|c|}
\hline $\begin{array}{c}\text { Author (s) } \\
\text { and } \\
\text { Year of } \\
\text { Publication }\end{array}$ & $\begin{array}{l}\text { Title of the } \\
\text { Research }\end{array}$ & $\begin{array}{c}\text { Place } \\
\text { or } \\
\text { country } \\
\text { of Publication }\end{array}$ & Database & Sample & Study Design \\
\hline $\begin{array}{l}\text { Cachón- } \\
\text { Zagalaz, et.al., } \\
(2020)\end{array}$ & $\begin{array}{l}\text { Systematic review } \\
\text { of the literature } \\
\text { about the effects } \\
\text { of the COVID-19 } \\
\text { pandemic on the } \\
\text { lives of school } \\
\text { children. }\end{array}$ & Spain & PubMed & $\begin{array}{l}9 \text { articles focusing } \\
\text { on an age of up to } \\
12 \text { years about } \\
\text { Covid-19 and } \\
\text { children and } \\
\text { psychological and } \\
\text { motor } \\
\text { characteristics of } \\
\text { children during } \\
\text { confinement }\end{array}$ & $\begin{array}{l}\text { Systematic } \\
\text { Review }\end{array}$ \\
\hline
\end{tabular}




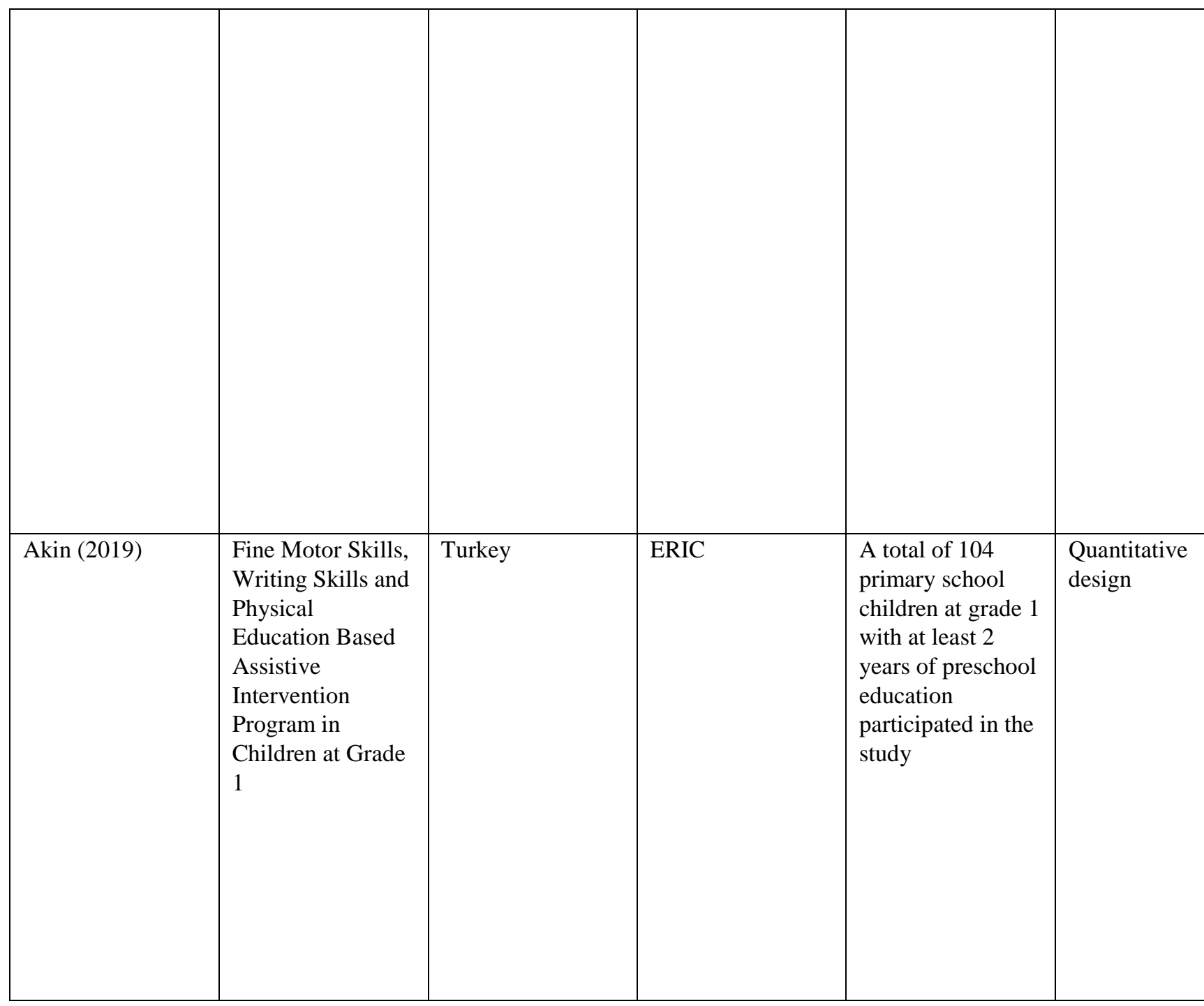




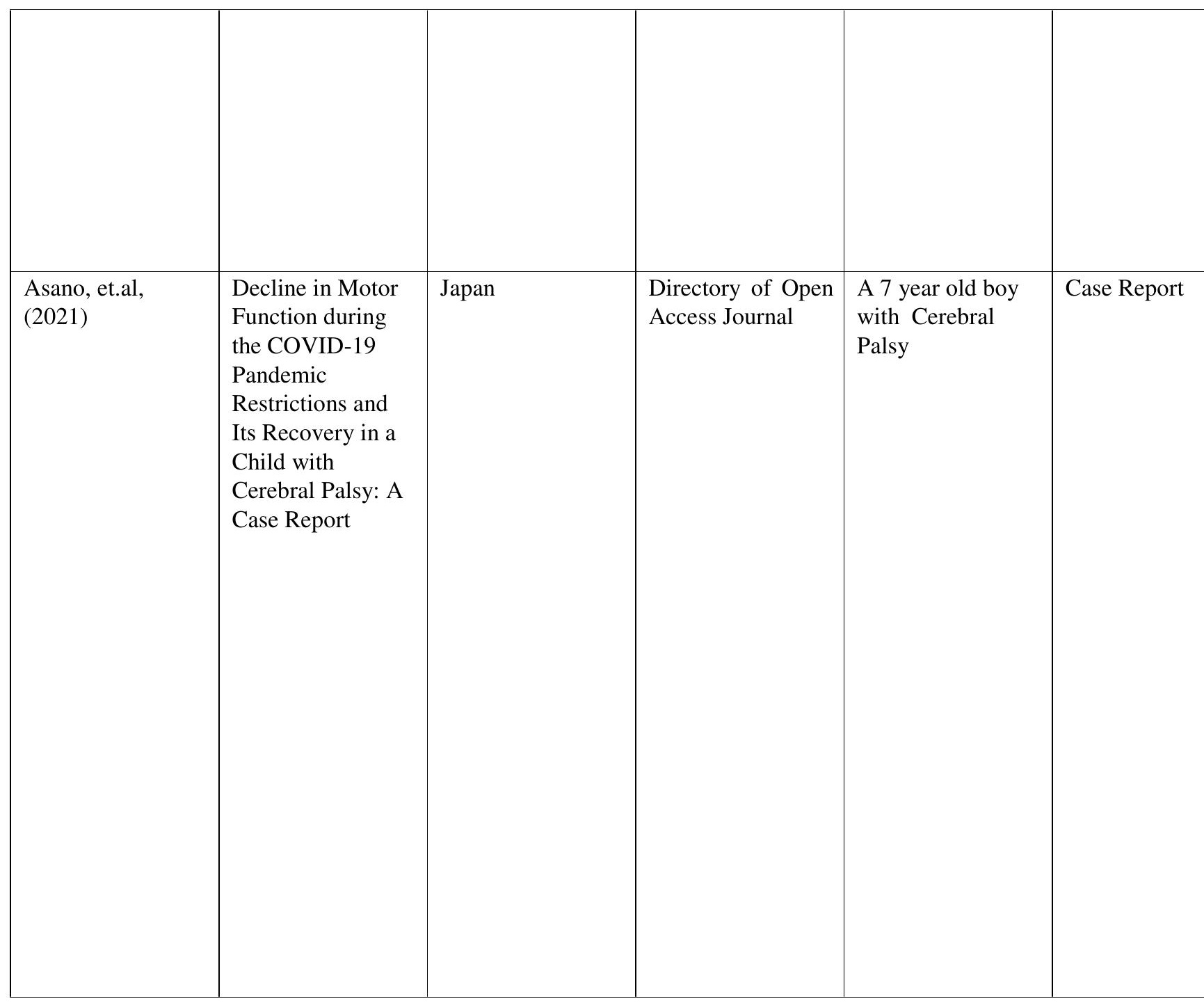




\begin{tabular}{|c|c|c|c|c|c|}
\hline $\begin{array}{l}\text { Ozdowska, et.al., } \\
(2021)\end{array}$ & $\begin{array}{l}\text { Using assistive } \\
\text { technology with } \\
\text { SRSD to support } \\
\text { students on the } \\
\text { autism spectrum } \\
\text { with persuasive } \\
\text { writing }\end{array}$ & $\begin{array}{c}\text { Australia } \\
\text { (Sunshine Coast) }\end{array}$ & ERIC & $\begin{array}{l}\text { Eight primary } \\
\text { school students on } \\
\text { Autism Spectrum } \\
\text { between the ages } \\
\text { of } 9 \text { and } 12 \\
\text { participated in this } \\
\text { single-subject } \\
\text { study }\end{array}$ & $\begin{array}{l}\text { ABAC study } \\
\text { design }\end{array}$ \\
\hline $\begin{array}{l}\text { Nyström, et.al., } \\
(2020)\end{array}$ & $\begin{array}{l}\text { International study } \\
\text { of movement } \\
\text { behaviors in the } \\
\text { early years } \\
\text { (SUNRISE): } \\
\text { results from } \\
\text { SUNRISE } \\
\text { Sweden's pilot and } \\
\text { COVID-19 study }\end{array}$ & Sweden & PubMed & $\begin{array}{l}100 \text { pre-school } \\
\text { learners ( } 58 \text { boys } \\
\text { and } 42 \text { girls) } \\
\text { between the age of } \\
\text { three and five of } \\
\text { age }\end{array}$ & Pilot study \\
\hline
\end{tabular}




\section{Discussion}

As the Covid-19 pandemic has spread outwards from its initial epicenter in China, Wuhan since December 2019, Namibia has not been spared the Covid-19 related impacts. Consequently, the state of emergency was declared by his excellency Dr. Hage Geingob on the 17th March 2020. Lockdowns have been imposed in an attempt to curb the spread of the virus. The following is how the series of lockdowns were scheduled in Namibia in 2020 from March to June.

The first lockdown started from the 27th March 2020 to - 16th of April 2020 with eight cases as of 26th March 2020. The measures which were put in place included the ban on international travel, all borders were closed except Hosea Kutako International Airport and for essential supplies from neighboring countries and travel restrictions for Khomas and Erongo Regions.

The second lockdown commenced on the 17th April 2020 - 4th May 2020 with 16 cases as of 17th April 2020. The measures which were put in place included the extension of the lockdown and restrictions on mass gatherings.

The third lockdown commenced on the 5th May 2020 - 1st June 2020 with 16 cases as of 5th May 2020. The measures which were put in place included nationwide lockdown with more measures including prohibiting the buying and selling of alcohol, restrictions on mass gatherings, the mandatory wearing of masks in public places, and gradual-reopening of face-to-face teaching.

The fourth lockdown commenced on the 2nd June 2020 - 28th June 2020 with 25 cases as of 2nd June 2020. The measures which were put in place included nationwide lockdown with some relaxation including on sale of alcohol, Erongo region remained in total lockdown, restrictions on mass gatherings, the mandatory wearing of masks in public places, and gradual reopening of face to face teaching.

Based on the above, it may be deduced that the lockdowns that happened in Namibia in 2020 may have affected the fine motor skills of learners, especially those who were starting with pre-primary education up to grade 3 as they needed the teacher to be on site with them as they are scaffolded into learning how to write to enhance their fine motor skills. It appears to be that learners who were doing pre-primary and those who were in grade one in 2020 did not enjoy their right of sitting in class and be taught by the more knowledgeable other as they were compelled to stay at home due to the Covid-19 pandemic and as result, they could not learn how 
to write neither how to grasp a pen or position their books and teachers resorted to sending written activities to the learners back home either as hard copies or electronically. Most of the activities seem to have been completed by the learners' siblings or the parents themselves to relieve themselves of the burden of teaching their children how to write as they view it to be a strenuous exercise. As these happen, learners are left with no knowledge of knowing how to write and their fine motor skills are not in any way enhanced thus resulting in the skill declining. In the same light of thought, during the pandemic, no movement was allowed and everybody had to stay home and as a consequence, learners could not do any movements such as playing to enhance their motor skills by they were compelled to watch television, sleep, or just eating.

Meanwhile, it is important to note that early childhood development includes acquiring fine and gross motor skills. Fine motor skills involve the movement of the smaller muscle groups in your child's fingers, hands, and wrists (Higuera, 2018). She further notes that fine motor skills are especially crucial, however, because the ability to use the smaller muscles in the hands allows children to perform self-care tasks without assistance. This includes: brushing their teeth, eating, writing, and getting dressed. This paper put more emphasis on writing as a fine motor skill. With the Covid-19 pandemic, it is crucial to prevent Junior Primary learners' fine motor skills from declining despite the pandemic that is preventing schools to operate normally.

In this literature research conducted by Cachón-Zagalaz, Sánchez-Zafra, Sanabrias-Moreno, GonzálezValero, Lara-Sánchez, and Zagalaz-Sánchez (2020) about the systematic review of the literature about the effects of the COVID-19 pandemic on the lives of school children reported on the 9 articles focusing on the age of up to 12 years about Covid-19 and children and psychological and motor characteristics of children that during the Covid-19 lockdowns, children were confined in different settings and the confinement has affected children under 12 at the motor and psychological levels. In addition, a study conducted in Turkey by Akin (2019) regarding fine motor skills, Writing Skills and education based mostly helpful Intervention Program in kids at Grade one reveal that physical education-based intervention programs for little muscle teams absolutely affects children's fine motor skills development and so their interest in writing and schooling. Moreover, the study recommends that it's essential to develop intervention strategies to facilitate the event of fine motor skills of grade one kids in school. to take care of an equivalent light-weight of thought, Asano, Kikuchi, Yamakawa, and Morioka (2021) in their case report regarding the decline in Motor operate throughout the COVID-19 Pandemic Restrictions and Its Recovery in an exceedingly kid with encephalopathy postulate that even the kids with encephalopathy were affected as they might not see their doctors for therapy either work on their fine motor skills as they were continuously inside. As a result, their fine motor skills 
diminished similarly as attributed to a coffee level of education. the same case was additionally reported in Kingdom of Sweden by Nyström, Alexandrou, Henström, Nilsson, Okely, El Masri, and Löf (2020) in a global pilot study of movement behaviors within the early years wherever one hundred pre-school learners (58 boys and forty-two girls) between the age of 3 and 5 old-time participated within the study and also the results were that the learners' fine motor skills weren't compact because the learners were allowed to play despite the pandemic. This was obtained by testing fine motor skills whereby learners WHO were finding out remotely were tasked to repeat shapes and drawings of the person and rate their mastery of fine motor skills. a special study by conducted in Australia by Ozdowska, Wyeth, Carrington, and Ashburner (2021) exploitation helpful technology with SRSD to support students on the syndrome spectrum with persuasive writing with eight school students on the syndrome Spectrum between the ages of nine and twelve participated during this single-subject study shows that in several cases the standard and/or length of written compositions and feelings of self-efficacy towards persuasive writing of scholars on the AS improved after they received physical and/or abstract writing supports. In light-weight of those results, one could infer that fine motor skills are necessary for children's development because it helps them to jot down quality papers.

\section{Conclusion and Recommendations}

This paper examined however the Covid-19 pandemic affects the fine motor skills of learners within the Junior Primary part to deduce ways that to stop learners' fine motor skills from decreasing.it so adopted a literature review technique employing a comprehensive strategy of looking for articles in varied analysis journal databases. The databases used are PubMed, Education Resources Information Center (ERIC), and Directory of Open Access Journals. within the end, the Covid-19 pandemic has resulted in an exceedingly decrease in fine motor skills thanks to kids being helped on the writing method by non-experts in terms of a way to hold a pen, a way to hold a book and the way to spell letters. This could imply that if this remains uncurbed it should have a nasty impact on junior primary learners as most of them might find yourself not knowing a way to write or find yourself having handwriting that's not appealing. To mitigate the matter from deteriorating, this paper suggests that despite the pandemic, strict measures ought to be place in situ whereas making certain that each one learners from pre-primary to grade three within the government colleges follow the route of the personal colleges in Namibia wherever they are doing not alternate about to faculty however they rather attend faculty a day so they will gain the mandatory skills on a way to write and oldsters ought to additionally play their role to make sure that their kids follow on a way to write reception to know and enhance their fine motor skills. Moreover, future analysis is required on fashioning methods of attending face- 
to-face categories on a day to day instead of alternating whereas making certain that the Covid-19 protocols ar adhered to by colleges in every and each room.

\section{Acknowledgements}

The authors would like to thank the almighty God for being faithful. Without his will we could not have finished and publish this paper. For that, we return the honour unto him.

\section{References}

Akin, S. (2019). Fine Motor Skills, Writing Skills and Physical Education Based Assistive Intervention Program in Children at Grade 1. Asian Journal of Education and Training, 5(4), 518-525.

Alston, J., \& Taylor, J. (1987). Handwriting: Theory, research and practice. Nichols Publishing Company, PO Box 96, New York, NY 10024.

Asano, D., Kikuchi, N., Yamakawa, T., \& Morioka, S. (2021). Decline in Motor Function during the COVID19 Pandemic Restrictions and Its Recovery in a Child with Cerebral Palsy: A Case Report. Children, 8(6), 511.

Berninger, V. W. (2009). Highlights of programmatic, interdisciplinary research on writing. Learning disabilities research \& practice, 24(2), 69-80.

Bingham, G.P. \& Snapp-Childs, W. (2019). Training children aged 5-10 years in manual compliance control to improve drawing and handwriting. Human Movement Science, 65, 42-50. Available at: https://doi.org/10.1016/j.humov.2018.04.002.

Cachón-Zagalaz, J., Sánchez-Zafra, M., Sanabrias-Moreno, D., González-Valero, G., Lara-Sánchez, A. J., \& Zagalaz-Sánchez, M. L. (2020). Systematic review of the literature about the effects of the COVID19 pandemic on the lives of school children. Frontiers in Psychology, 11.

Cahill, S.M. (2009). Where does handwriting fit in? Strategies to support academic achievement. Intervention in School and Clinic, 44(4), 223- 228. Available at: https://doi.org/10.1177/1053451208328826.

Feder, K. P., \& Majnemer, A. (2007). Handwriting development, competency, and intervention. Developmental Medicine \& Child Neurology, 49(4), 312-317. 
Gómez-Gerdel, M. A. (2020). The full brain of the child: The work of a teacher of inclusive education with families in times of confinement. An educational reflection. Rev. Int. Educ. Justice Soc, 9, 1-10.

Hidayat, N. R., Asdi, R., \& Fitria, N. (2020, September). Role of Parents in Improving Children's Fine Motor Skills at Home during the COVID-19 Pandemic. In Proceedings of the 4th International Conference on Learning Innovation and Quality Education (pp. 1-4).

Higuera, V. (2018, November 30). How to Help Your Child Develop Fine Motor Skills: Fine motor skills meaning. Healthline. https://www.healthline.com/health/fine-motor-skills

Lamme, L. L. (1979). Handwriting: In an early childhood curriculum. Young Children, 20-27.

Maeland, A. F. (1992). Handwriting and perceptual-motor skills in clumsy, dysgraphic, and 'normal'children. Perceptual and motor skills, 75(3_suppl), 1207-1217.

Moore, R. L., \& Rust, J. O. (1989). Printing errors in the prediction of academic performance. Journal of School Psychology, 27(3), 297-300.

Nyström, C. D., Alexandrou, C., Henström, M., Nilsson, E., Okely, A. D., El Masri, S. W., \& Löf, M. (2020). International study of movement behaviors in the early years (SUNRISE): results from SUNRISE Sweden's pilot and COVID-19 study. International journal of environmental research and public health, 17(22).

Ozdowska, A., Wyeth, P., Carrington, S., \& Ashburner, J. (2021). Using assistive technology with SRSD to support students on the autism spectrum with persuasive writing. British Journal of Educational Technology, 52(2), 934-959.

Shams, L. \& Kim, R. (2010). Bayesian priors and multisensory integration at multiple levels of visual processing: Reply to comments on-crossmodal influences on visual perceptionll. Physics of Life Reviews, 7(3), 295-298. Available at: https://doi.org/10.1016/j.plrev.2010.07.006.

Stevenson, N. C., \& Just, C. (2014). In early education, why teach handwriting before keyboarding? Early Childhood Education Journal, 42(1), 49-56.

Tseng, M. H., \& Cermak, S. A. (1993). The influence of ergonomic factors and perceptual-motor abilities on handwriting performance. American Journal of Occupational Therapy, 47(10), 919-926. 
Volman, M., Van Schendel, B.M \& Jongmans, M.J. (2006). Handwriting difficulties in primary school children: A search for underlying mechanisms. American Journal of Occupational Therapy, 60(4), 451-460. Available at: https://doi.org/10.5014/ajot.60.4.451.

Wilhelm, I., Prehn-Kristensen, A., \& Born, J. (2012). Sleep-dependent memory consolidation-what can be learnt from children?. Neuroscience \& Biobehavioral Reviews, 36(7), 1718-1728. 